\title{
Analysis of Infra-Red Laser Power Process Using Response Surface Methodology
}

\author{
${ }^{1}$ Wahaizad Bin Safiei, ${ }^{2}$ Mohd Rashdan Bin Ab Rashid \\ ${ }^{1}$ Faculty of Engineering Technology, University Malaysia Pahang, 26300, Kuantan, Pahang, Malaysia \\ ${ }^{2}$ Faculty of Mechanical Engineering, Universiti Teknologi Malaysia, Johor, Malaysia \\ $\frac{{ }^{1} \text { wahaizad@ump.edu.my }}{{ }^{2} \text { mrar82@gmail.com }}$
}

\begin{abstract}
High-quality products and shorten manufacturing lead time are very important factors addressed by many companies. Typically, low-quality products are induced by inconsistent of manufacturing process performance. To get a constant laser power in Infrared (IR) Laser Marking process was a common problem facing by many engineers in the manufacturing industry. This consequences might effect on laser marking characteristics such as the possibility of burn marking or blur marking particularly on the products. Therefore, the objective of this paper is to study the interaction between Infrared (IR) Laser Marking input parameters such as current (amp), frequency (Hz), water flow (l/min) and laser beam size (mm) on laser power (watt) as the main response. Furthermore, the response of laser power from Infra-Red laser process can be predicted when all combinations of parameters are tested. The IR marking machine was deployed and experimental studies were conducted in order to meet this objective. The experiments were based on Design of Experiment (DOE) and Response Surface Methodology (RSM) because second order model or polynomial equation was needed to fit for the response. The relationship between input and output parameters can be visualized by $3 D$ graphs which were developed from Mathematical modeling. Based on the experiment results, the parameters that have significant effects on the laser power are current, laser beam size and water flow. However, frequency does not have a significant factor in this study.
\end{abstract}

Index Terms- Infrared (IR) laser marking, current, frequency, water flow, and laser beam size, laser power, response surface methodology, design of experiment.

\section{INTRODUCTION}

Laser application is widely used not only in the manufacturing but also in the medical field. Besides metal cutting process which integrated with numerical control (NC) for axes motion, alphanumeric marking also applied laser capabilities but with lesser penetration rate. Company's logo, alphanumeric, barcode number and product's ID are examples of laser marking applications in the industry. The laser which is an acronym for "Light Amplification by Stimulate Emission of Radiation" has many advantages such as high productivity, flexible penetration rate and easy to cut harder materials.

Stable laser power is very crucial for any manufacturing process related to the laser. If there are variations in terms of laser power, it could potential damage the products or the products no longer can be used. As a result, high-yield performance would not able to achieve if the problem remains. Electronics and semiconducting lasers are multilayer semiconductor devices that generate a coherent beam with specific size of monochromatic light by laser action. 
Technically, in order to get consistent laser power, a diode, and the lens must be in a good condition. The diode is a source of light which it will deteriorate along the time. Furthermore, mechanical alignment and parameter settings also are critical prior to getting good laser power. From time to time, laser power must be measured especially before the laser marking process happen. This is to avoid any degradation of laser power. Generally, statistically process control is being used to monitor the laser power. This is a normal practice in the industry by technical personnel to ensure the laser marking process does not induce any defects on the products. Figure 1 shows a schematic diagram on how the IR laser is produced.

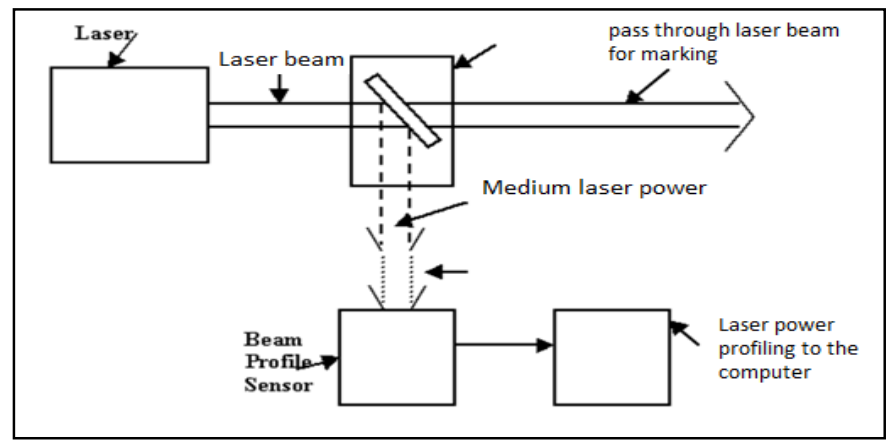

Figure 1 Mechanism on how IR laser is produced

\section{LITERATURE REVIEW}

The laser marking machine is one of the useful machine that process for the production in the semiconductor industry where the application to mark to their product as such as on the metal, plastics, ceramics, glass, wood and leather as well as painted surfaces and photographic emulsions. Golub et al carried out experimental study for focused-beam interaction with rubber, wood, fabric, and plastics for the case of a 30-W infra-red laser. From the experimental results, effective laser heathardening of steel is achieved by $3-\mathrm{kW} \mathrm{CO}$ which laser by means of a computer-generated reflective focusator [1]. There are a more or less pronounced burning or ablation of the surface such as plastics and varnishes which basically leads to a relief structure. Hofman et al developed a method to mark plastic materials by using laser pulses of shorter wavelength as the main factor to the process which are not absorbed by the tested material [2]. There were importance methods that using the techniques to enhance the power densities to levels sufficient to etch the surface of the material to be marked. One of the most fundamental laser profile measurements is the beam width. It is a measurement of primary significance because it affects many other beam parameters. For example, the beam width gives the size of the beam at the point where measured. A statistical measurement of the width of the beam is also a significant factor in determining the stability of the laser output. [3] The significance of the beam profile is that the energy density, the concentration, and the collimation of the light are all affected by it. Also, the propagation of the beam through space is significantly affected by the beam profile. [3]. The most popular systems are lamp-pumped Nd: YAG lasers, which produce near-infrared light at a wavelength of $1,064 \mu \mathrm{m}$, and CO2 lasers, which produce light at the $10.64 \mu \mathrm{m}$ wavelength.

\section{RESEARCH METHODOLOGY}

The experiments were performed on IR Laser Marking machine. The laser marking input parameters selected are current, frequency, water flow and laser beam size. The output parameter of laser process is called laser power which measures in Watt. There are many factors influence the output parameter in any laser marking process which are voltage, current, frequency, cooling rate, size diameter of laser and much more. The experiments were performed under the designed full factorial procedure. Table 1 shows factor and level for laser marking parameters. The output response study is Laser Power (Watt). 
Table 1 The factors and level for laser power check experiment data.

\begin{tabular}{|c|c|c|c|c|c|}
\hline No. & Parameter & Unit & $\begin{array}{c}\text { Low } \\
\text { Level (-) }\end{array}$ & $\begin{array}{c}\text { High Level } \\
(+)\end{array}$ & $\begin{array}{c}\text { Center } \\
\text { point }\end{array}$ \\
\hline A & Current & Ampere & 25 & 35 & 30 \\
\hline B & Frequency & Hertz $(\mathrm{Hz})$ & 10000 & 30000 & 20000 \\
\hline C & Water flow & $\mathrm{l} / \mathrm{min}$ & 6.5 & 11.5 & 9 \\
\hline D & Laser beam size & $\mathrm{mm}$ & 1.00 & 1.40 & 1.20 \\
\hline
\end{tabular}

The 24 experiment with 4 center points had been conducted for the full factorial experiment. In the actual experiment, all the analysis were based on RSM with face-centered central composite design (FCCD) or face central cube design (FCD). Design Expert Software version 9 was employed to determine the main effects of the process parameters. Analysis of variant (ANOVA) was performed to find the dependent variables that affect the laser power as an output response. The analysis of variance (ANOVA), full factorial experiment, and central composite design (CCD) experiment was conducted in order to discover the most significant factors as well as to develop mathematical models of the IR laser marking machine output response.

\section{RESULT AND ANALYSIS}

Based on full factorial design analysis, it was found that the responses give a significant curvature. From ANOVA table, curvature was significant when Prob $>F$ is less than 0.05. Therefore, a polynomial of a higher degree such as second order model had been used for further analysis. Based on Table 3, it shows experimental results for Laser Power in laser marking IR machine (CCD). From CCD ANOVA table, the ranking for input parameter that the most influence on the laser power (watt) is able to determine by referring the value of Prob $>$ F. Table 2 describes the highest influence parameters until the lowest significant effect on Laser Power (Watt). Mathematical modeling or regression model obtained from CCD as below in equation 1.1. and 1.2 where model fit for a quadratic equation. Both equations were derived based on RSM data analysis from Design Expert software. The final equation can be classified in terms of coded factors and actual factors. 
INTERNATIONAL JOURNAL OF ENGINEERING TECHNOLOGY AND SCIENCES (IJETS) Vol.6 (1) Dec 2016 DOI: http://dx.doi.org/10.15282/ijets.6.2016.1.5.1055

Table 2 Experimental results for Laser Power in laser marking IR machine (CCD)

\begin{tabular}{|c|c|c|c|c|c|c|}
\hline & & Factor : A & Factor : B & Factor: $\mathrm{C}$ & Factor: D & Response 1 \\
\hline Std & Run & Current (Amp) & $\begin{array}{l}\text { Frequency } \\
(\mathbf{H z})\end{array}$ & $\begin{array}{c}\text { water flow } \\
\text { (1/min) }\end{array}$ & $\begin{array}{l}\text { Laser Bem } \\
\text { size }(\mathbf{m m})\end{array}$ & $\begin{array}{l}\text { Laser power } \\
\text { (Watt) }\end{array}$ \\
\hline 15 & 1 & 25 & 30000 & 11.5 & 1.4 & 8.929 \\
\hline 5 & 2 & 25 & 10000 & 11.5 & 1 & 3.388 \\
\hline 13 & 3 & 25 & 10000 & 11.5 & 1.4 & 8.207 \\
\hline 16 & 4 & 35 & 30000 & 11.5 & 1.4 & 40.057 \\
\hline 10 & 5 & 35 & 10000 & 6.5 & 1.4 & 45.288 \\
\hline 25 & 6 & 30 & 20000 & 9 & 1.2 & 15.663 \\
\hline 7 & 7 & 25 & 30000 & 11.5 & 1 & 3.708 \\
\hline 3 & 8 & 25 & 30000 & 6.5 & 1 & 3.693 \\
\hline 9 & 9 & 25 & 10000 & 6.5 & 1.4 & 7.874 \\
\hline 14 & 10 & 35 & 10000 & 11.5 & 1.4 & 38.202 \\
\hline 4 & 11 & 35 & 30000 & 6.5 & 1 & 29.534 \\
\hline 12 & 12 & 35 & 30000 & 6.5 & 1.4 & 46.847 \\
\hline 2 & 13 & 35 & 10000 & 6.5 & 1 & 28.049 \\
\hline 27 & 14 & 30 & 20000 & 9 & 1.2 & 15.773 \\
\hline 21 & 15 & 30 & 20000 & 6.5 & 1.2 & 16.213 \\
\hline 22 & 16 & 30 & 20000 & 11.5 & 1.2 & 15.200 \\
\hline 11 & 17 & 25 & 30000 & 6.5 & 1.4 & 8.773 \\
\hline 18 & 18 & 35 & 20000 & 9 & 1.2 & 33.700 \\
\hline 23 & 19 & 30 & 20000 & 9 & 1 & 11.100 \\
\hline 24 & 20 & 30 & 20000 & 9 & 1.4 & 30.033 \\
\hline 1 & 21 & 25 & 10000 & 6.5 & 1 & 3.213 \\
\hline 17 & 22 & 25 & 20000 & 9 & 1.2 & 5.407 \\
\hline 19 & 23 & 30 & 10000 & 9 & 1.2 & 14.800 \\
\hline 26 & 24 & 30 & 20000 & 9 & 1.2 & 15.758 \\
\hline 20 & 25 & 30 & 30000 & 9 & 1.2 & 16.113 \\
\hline 28 & 26 & 30 & 20000 & 9 & 1.2 & 15.820 \\
\hline 8 & 27 & 35 & 30000 & 11.5 & 1 & 27.261 \\
\hline 6 & 28 & 35 & 10000 & 11.5 & 1 & 26.232 \\
\hline
\end{tabular}

Table 3 Input parameter ranking that effect on the output response, laser power

\begin{tabular}{|c|c|r|r|}
\hline \multicolumn{4}{|c|}{ Analysis of variance table [Partial sum of squares - Type III] } \\
\hline \multirow{2}{*}{$\begin{array}{c}\text { Rank } \\
\text { No. }\end{array}$} & Source & F & p-value \\
\cline { 2 - 4 } & Model & 1002.61 & $<0.0001$ \\
\hline 1st & A-Current & 140.39 & $<0.0001$ \\
\hline 2nd & D-Laser Beam Size & 28.86 & $<0.0001$ \\
\hline 3rd & $D^{\wedge}$ & 25.69 & $<0.0001$ \\
\hline 4th & $A D$ & 5.71 & 0.0263 \\
\hline 5th & $A C$ & 4.89 & 0.0382 \\
\hline 6th & $C$-Water Flow & & \\
\hline
\end{tabular}


INTERNATIONAL JOURNAL OF ENGINEERING TECHNOLOGY AND SCIENCES (IJETS) Vol.6 (1) Dec 2016 DOI: http://dx.doi.org/10.15282/ijets.6.2016.1.5.1055

Both equations can be used to make predictions about the response for given levels of each factor.

Final Equation in Terms of Coded Factors:

Laser power $=16.44+14.55 \mathrm{~A}-1.02 \mathrm{C}+5.45 \mathrm{D}-1.17 \mathrm{AC}+2.47 \mathrm{AD}+4.13 \mathrm{D}^{2}$

Final Equation in Terms of Actual Factors:

Laser Power $=+112.65011+0.78464 *$ Current $+2.39007 *$ Water Flow $-294.83514 *$ Laser Beam Size $-0.093227 *$ Current * Water Flow $+2.47104 *$ Current * Laser Beam Size $+103.30602 *$ Laser Beam Size^2

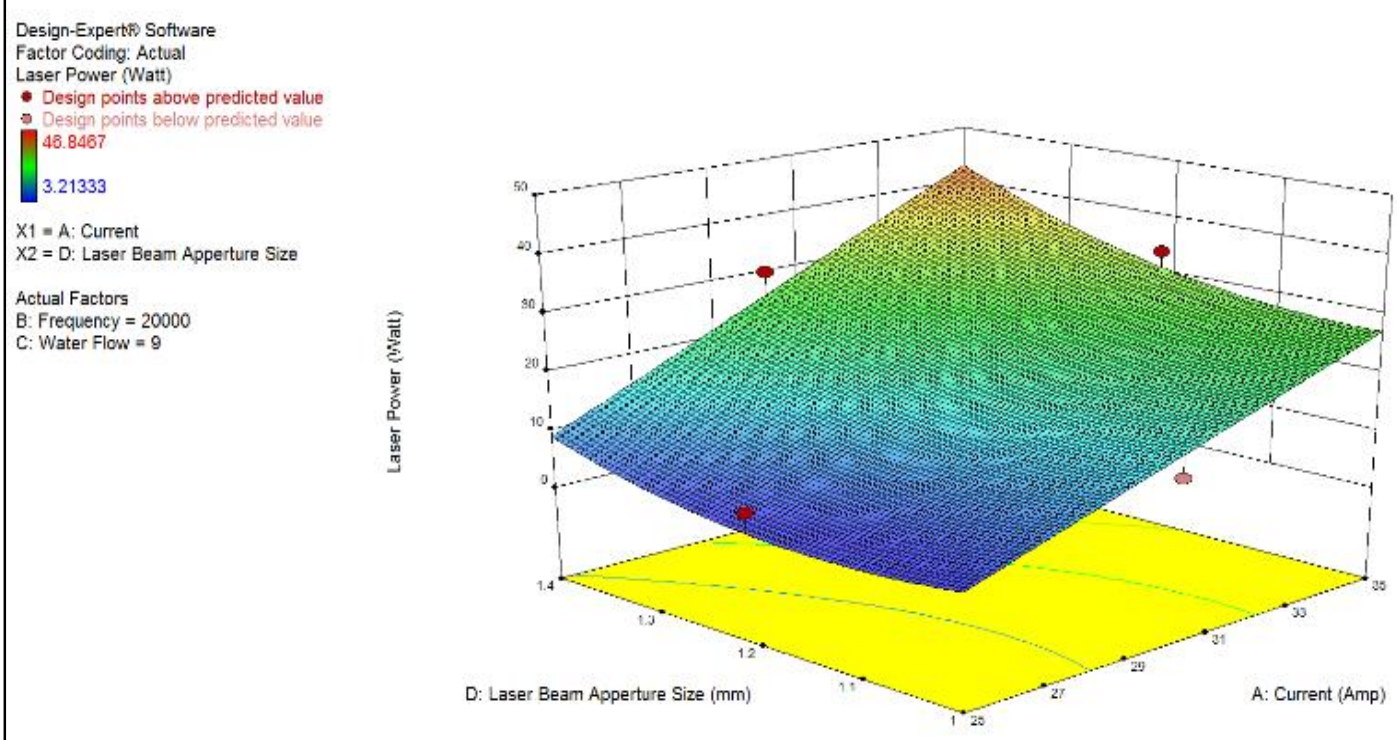

Figure 2 3D response surface for Laser power in laser marking IR machine (AD) interaction

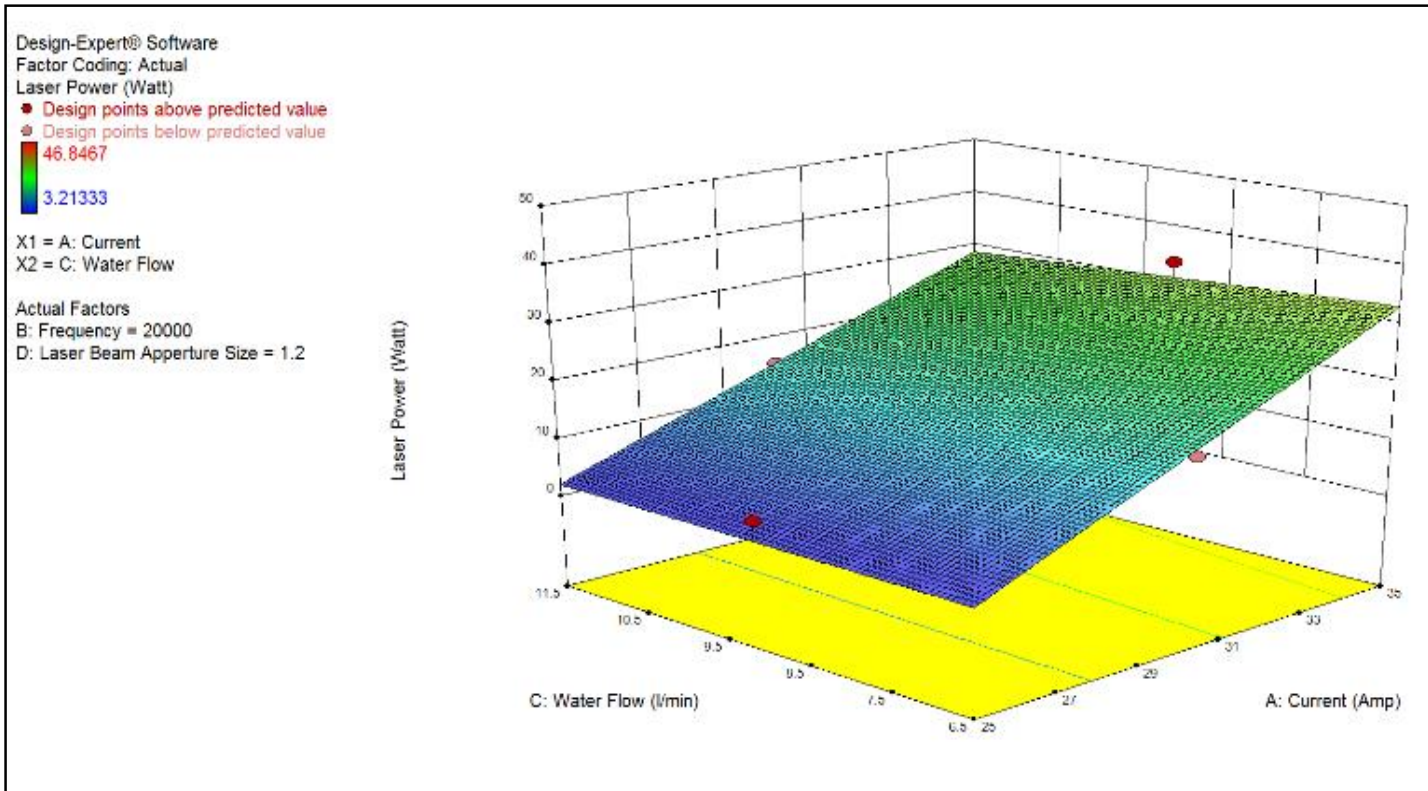

Figure 3 3D response surface for laser power in laser marking IR machine (AC) interaction 
Theoretically, the size of laser which typically in diameter is depending on many factors including the tooling. The Laser Power (Watt) would increase significantly when the size of tooling change from small hole to the big one. Figure 2 shows that the interaction between the current and laser beam size,(AD). Basically, when machine settings for current and laser beam size set at a high value, higher Laser Power (Watt) was able to obtain. Figure 3 shows the 3D graph from the interaction between current and water flow (AC) affecting Laser Power (Watt). In order to obtain higher laser power, current (amp) must set at a high level, but water flow needs to set at low level. When water flow circulates inside the cooling compartment, less heat would be losses to surrounding. It means more energy of current (Amp) able to absorb, thus, gives better performance to produce Laser Power (Watt). Therefore, slow water flow is a must prior to getting higher Laser Power (Watt). All these three factors are statistically significant to the Laser Power (Watt).

Confirmation run was conducted in order to evaluate margin error between theoretically prediction and confirmation test results. Basically, the objective of confirmation run is to evaluate whether the optimum parameters predicted were in allowable range. The margin error should be less than $15 \%$ $[8,9]$. Based on confirmation run, all the results are less than $15 \%$, thus, indicating the model that were developed for current, frequency, water flow and laser beam size are reasonable accurate. All the actual values are within $95 \%$ prediction interval (PI). A total three confirmation tests had been carried out consists of three-run for entire inputs parameter as well.

\section{CONCLUSION AND RECOMMENDATION}

Conclusion

- $\quad$ All parameters selected for this experiment current, frequency, water flow, and laser beam size are able to rank from the highest to the lowest influences to the laser power.The Frequency $(\mathrm{Hz})$ does not have significant effects on the responses in RSM.

- Mathematical models developed to predict the various machine characteristics are statistically valid and sound within the range of the factors investigated.

- The margin error obtained from all responses studied in this research were all accepted as the results within prediction interval (PI).

Recommendation

- The parameter range must be re-evaluated especially for current (amp) which optimum condition of IR laser marking process can be obtained.

- $\quad$ Other response can be studied such as laser groove for the same input parameters. 


\section{REFERENCES}

[1] M.A. Golub, I.N. Sisakyan \& V.A. Soifer (1991). Infra-red Radiation Focusators : Optics and Lasers in Engineering 15 (1991) 297-309.

[2] M. Hofmann, F. Breitenfellner, N. Buhler, R. C. Sykes and H. Gugger (1987). High Contrast and intact Surface - a Challenge in Laser Marking of Plastics : Lasers in Motion for Industrial Applications, 156 (January 1, 1987).

[3]Josephine Peter*, B. Doloi and B. Bhattacharyya, (2013). Analysis on the characteristics of Nd: YAG laser marking on alumina ceramic based on RSM.

[4]Ashraf F. El-Sherif, Mahmoud M. Talat (2012). Diode Pumped High Peak Power Quasi QSwitched and Passively Q-Switched Nd: YVO4 Lasers at $1064 \mathrm{~nm}$ and $532 \mathrm{~nm}$ Using Cr:YAG and KTP Crystals

[5]Carlos B. Roundy, Ph.D. Current technology of laser beams profile measurements, Technical Report

[6]Montgomery, D. C. (2001). Design and Analysis of Experiments. 8th ed. Singapore: John Wiley \& Sons, Inc. 501-507.

[7]Sivaraos, *, K.R.Milkey, A.R.Samsudin, A.K.Dubey, P.Kidd (2014). Comparison between Taguchi Method and Response Surface Methodology (RSM) in Modelling CO2 Laser Machining. Pages 35 42.

[8]Mohd Halimuddin (2010) . Performance Evaluation of Electrical Discharge Machining on Titanium Alloy Using Copper Impregnated Graphite Electrode. Universiti Teknologi Malaysia : Master Thesis

[9] Mas Ayu (2006). Performance Evaluation of Wire Electrode Discharge Machining (WEDM) On Tungsten Carbide. Universiti Teknologi Malaysia: Master Thesis. 